\title{
Bayesian Model of Multisensory Comfort and Adaptation in Intelligent Building
}

\author{
Sid Ahmed Mokhtar MOSTEFAOUI, Lynda Zaoui and Lahcene AID \\ Department of Computer Science, USTO-MB University, Oran BP 1505 El M'naouer \\ Bir El Djir 31000, Algeria \\ s_mostefaoui@esi.dz
}

\begin{abstract}
Understanding a building's ambiance and user's preferences and then providing corresponding comfort is substantial in a smart home environment. In this vork, we aim to design a model for an intelligent system (building) controller whose intelligence is adaptation, in changing situations, according to the preferences of occupants without their intervention. Adaptation, according to Humphreys is: "If a change occurs such as to produce discomfort, people react in ways which tend to restore their comfort". Therefore, our adaptive system restores comfort to the occupants based on their preferences, it has the ability to self-regulate and adapt to the climate conditions in buildings. In order to use adaptive control a model of the building is necessary and predictive control is very important because it includes a model for future disturbances. The starting point of this work was the modeling of multisensory comfort, and the dynantic and adaptive behavior of an occupant with his environment. A key elementyas to find a way to model these adaptive actions. To achieve our goal, we used Bayesian networks that are powerful tools for decision and reasoning under uncertainty.
\end{abstract}

Keywords: Intelligent blalding, multisensory comfort, adaptation, Bayesian network

\section{Introduction}

Nowadays, comfort is highity required in the field of buildings because of its impact on the quality of indoor environment atmosphere, health and productivity of people who live and spend almost the $3 / 4$ of their time indoor. But with the current needs of energy-saving and controlling environmental impacts of building, one may ask what definition could be given to comfort, how to produce it and keep its environmental conditions. Comfort is revealed to be difficult to define, since most of the people have an impetuous illustration of this concept but they can neither express it in a suitable way nor give and define criteria about what is comfortable. The notion of comfort is very labile and depends on the context. [1] defines comfort as an unidentified scientific object "U.S.O". In fact, to identify comfort means to know ts properties but this can be only obtained by a person with a subjective estimation towards "something" in a given context.

In building standards, approaches were set to define the notion of comfort and they deal with most of the work, the thermal surroundings of building. Thus it leads to two current definitions. The first being stated by [2] and it expresses a state of neutrality that is to say "the state of mind expresses satisfaction with its thermal environment". A second definition was proposed by [3], as part of his researches on thermal comfort, denotes that conditions for which the self-regulatory mechanisms of the body are at a minimum level of activity. 
However, this notion of comfort is complicated by the several parameters that it combines both human (perception) and physical (measurement).

Measure comfort is to determine and compare, for every type of comfort such thermal, acoustic, visual comfort and indoor air quality, the physical environment variables with a person judgment to the same environment. Current standards move toward comfort with an analytic and reductive approach of the reality within its complexity. Studies in situ revealed an overestimation of uneasiness level in reality. These studies were applied to set the basis of the adaptive approach which differentiates comfort through the adaptive interaction between the resident and his environment.

In the literature, several researches have been done with the aim of automating daily activities by designing adaptive smart home system. In [4] CASAS utilizes machine learning techniques in order to dynamically adapt to user advice or changes in daily routine activities. The adaptation capability of CASAS is achieved by utilizing data mining method as weil as learning strategies that adapt to the resident's explicit and implicit preferencerfeedback. In [5], adaptation is to retrain the preference model, in other words, the proposed system observes each interaction from users and then tries to provide its bes-estimated service automatically. Given the service, the users will feedback acceptance/rejection of the service to the system. In turn, the system, after analyzing the feedback, then infers the most probable labels for updating the original models involved.

The first part of our study aims and consists to define the intelligent building and the multisensory comfort, and then present the analytic and adapt ve approaches and the different model of sensorial comfort. The second part is allocated to the same context of intelligent building (DOMUS) and using adaptive-approach, we manage to design, with machine learning, a probabilistic (Bayesian) model reproducing the specific comfort ( thermal, acoustic, indoor air quality and visaal comfort), their involvement in multisensory comfort and the dynamic behavior of the occupants towards environment changes in the building. Finally to check the presentation of our model, we will use the N.fold cross validation which is a statistical method of eyaluating and comparing learning algorithms by dividing data into two segments: one used toleam or train a model and the other used to validate this model.

\section{Background}

\subsection{Smart Home}

Before defining a snarthome, we must begin with the definition of home automation and of ambient intelligence, these two sets of techniques converge, subsequently, to the smart home. The current definition of home automation is:" Set of techniques to integrate, in buildings, automation for security, energy management, communication...". In time, the different actors (academic, industrial, institutional) associated with home automation offered their ad hoc definitions. Ambient intelligence involves the concept of environment. In fact, it is to proyide a given environment (urban space, office, commercial spaces ...) digital capabilities: perceptual abilities (with different sensors), processing capabilities and reaction capabilities (with different effectors). Ambient intelligence involves many fields, especially the field of sensor networks (and implicitly networks actuators), the field of human-computer interaction and the field of artificial intelligence. For the definition of intelligent building, we choose one of [6] that the IB is one that crates an environment that maximizes the efficiency of the occupants of the building while at the same time allowing effective management of resources with minimum life-time costs. 
Intelligent buildings make good business sense. As the Information Age takes us to new heights, the Intelligent Building System (IBS) has the flexibility and modularity to accommodate every change. An intelligent premise distribution system will allow the owner, administrators, and occupants to take advantage of new technology as it becomes available, at a minimum cost and without a major disruption of the productivity of the office work space. Today's competitive society demands efficiency. In a typical building the power supplies, air conditioning systems (Heating, Ventilation and Air Conditioning HVAC), lighting, external fabric, security systems, and computers all operate independently; consequently, building management struggles to satisfy conflicting demands. But if one adds a comprehensive and integrated IBS and interrelates the various subsystems through a single control framework, then the building, factory, hotel, or other type structure can respond to its environment in a timely and cost-effective manner.

\subsection{Components of the Intelligent Building}

An IBS is the integration of a wide range of services and systems into a unified whole. In general terms the components are as follows [6]:

- Energy Management Systems (EMSs)

- Temperature Monitoring Systems (TMSs)

- Lighting Control and Reduction (LCRs)

Access and area locate systems

- Security systems

- Fire Life Safety (FLS)

- Network (ISDN)

- Office Automation (OA)

- Computer systems

- Local Area Networks (LATS)

- Management Information Systems (MISS)

- Cabling schemestand records

- Maintenance system

- Intelligent systems

\subsection{Multisensory Comfort:}

The quality of life in buildings (comfort conditions) is determined by several factors like: Thermal comfort visual comfort, and Indoor Air Quality (olfactory comfort) [7]. Thermal comfort and visual comfort are often confronted, especially, with assumed relationships between luminosity and thermal perception.

In their study, Candas and Dufour [8] they maintained, in a climate chamber in which a thermal anbiance "slightly warm" was applied, 48 subjects under two different lighting: one "hot" $\left(2700^{\circ} \mathrm{K}\right)$, the other "cold" $\left(5000^{\circ} \mathrm{K}\right)$. The results show that the thermal comfort perceived by participants in cold light was better than the thermal comfort perceived in hot lighting. The difference is small, but according to the authors, significant. If the relationship between thermal comfort and visual comfort have a major place in literature, other links have also been revealed by some studies. For example, experiments where Clausen and Fanger intervened [9], they highlight a link between the operative temperature, thermal comfort criterion, and the perception of the air quality. In 2002, Ernst and Banks [10] they realized an experiment to understand the links between visual modalities and haptic. Their results 
indicate that the sensation produced by these two modalities can be predicted in by probabilistic way, by sensors fusion technique. Similar works say these results, such as [11].

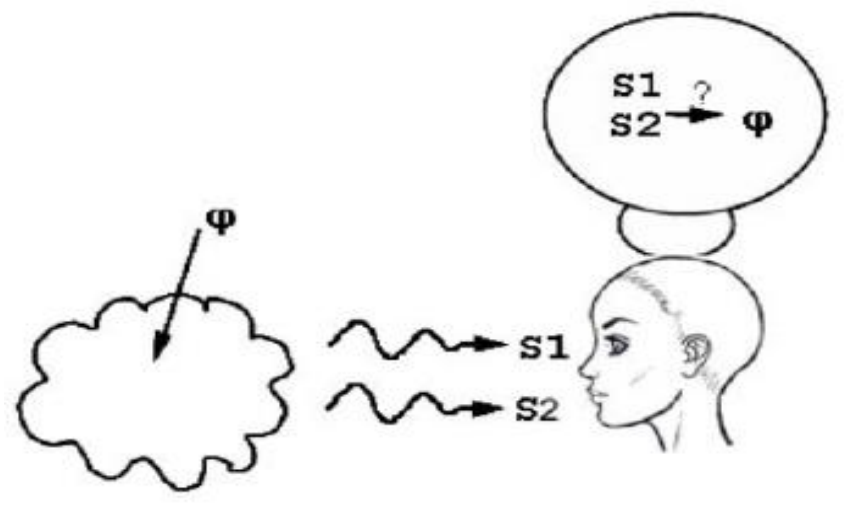

Figure 1. Human Perception and Integration of Sensations (S1 and S2) to Perceive a Phenomenon $\Psi$

\subsection{Models of Comfort}

\subsubsection{Analytical Models}

a) Thermal comfort model: Many analytical nodels (PMV PMV*, ET, SET*) have been developed to predict the thermal and physiological responses of the human body depending on environmental conditions, in stationary or transiênt conditions. In the simplest models, the body is treated as a single unit. More complex models divide the body into several segments and simulate the dynamics of physiological responses. We describe below PMV us the main model.

PMV (that has been adopted by the ISO 7730 standard) is calculated by Fanger's equation [12], with maintaining the stability of the heat balance of the human body (necessary but not sufficient condition for thermal comfort), Fanger's method is to determine analytically the heat exchange betwreen the subject and the environment. Then, depending on the difference between the produced and the dissipated heat (heat balance) by the dressed human body, it establishes an index "PMV" that predicts the mean thermal sensation vote on a standard scale for a large group of persons. The American Society of Heating Refrigerating and Air Conditioning Enginees (ASHRAE) developed the thermal comfort index by using coding -3 for cold, -2 for cool -1 for slightly cool, 0 for natural, +1 for slightly warm, +2 for warm, and +3 for hot

$$
\begin{aligned}
& P M V=[\quad 0,303 * \exp (-0,036 M)+0,028 \quad] * L \\
& L=M-\left(W+E_{d i f}+E_{r s w, r e q}+E_{r e s}+C_{r e s}+R+C\right)
\end{aligned}
$$

With:

L. The difference between produced and dissipated heat (thermal balance)

M: Internal heat generation (rate of metabolism), $\mathrm{W} / \mathrm{m}^{2}$

W: Power needed by the external work, W/m2

E: Latent heat flux exchanged by evaporation (dif: diffusion through the skin, rsw, req: required for comfort, res: respiratory evaporation), $\mathrm{W} / \mathrm{m}^{2}$

C: Heat flux exchanged by convection (res : respiratory convection), $\mathrm{W} / \mathrm{m}^{2}$

$\mathrm{R}$ : Heat flux exchanged by radiation, $\mathrm{W} / \mathrm{m}^{2}$ 
To determine the acceptability of the thermal environment, Fanger linked the PMV to another index, the "PPD" (Predicted Percentage Dissatisfied ), that establishes a quantitative prediction of the thermally dissatisfied people assuming establishes a quantitative prediction of the thermally dissatisfied people assuming that who votes $-2,-3,+2$ or +3 on the thermal sensation scale is dissatisfied.

$$
P P D=100-95 \times e^{-\left(0.03353 \times P M V^{4}+0.2179 \times P M V^{2}\right)}
$$

b) Visual comfort model: According Bodart [13], visual comfort is a sensation that is related to a clear and without fatigue perception of colorful and pleasant ambiance. Unlike thermal comfort, there isn't a general index expressing global form of visual comfort. The most common form to define the visual comfort is based on specific criteria like:

b.1. Characterization of light: Brightness is the main variable of visual comfort. Two main characteristics of a light are used as a criterion for comfort:

- Light intensity:The light intensity can be expressed in various physical quantities (it is expressed in lux). The other variables characterizing the light intensity correspond to sources, and they are used to estimate the contribution of these sources to the lightintensity.

- Spectral composition:The light can be characterized by its spectrum, corresponding to different colors (wavelengths) that constitute it. In the field of interior lighting, this constitution (spectral light) is expressed by color tempêrature (in degrees Kelvin). This correspondence is established from the radiation of a black body at different temperatures, and it is formalized by Planck's law Warm lighting is, paradoxically, a light whose temperature is low $(10000 \mathrm{~K})$, compared with a cold light when the temperature is higher (higher than $300000 \mathrm{~K}$ ). Lighting neutral temperature corresponds to a temperature of $27000 \mathrm{~K}$. The Kruithof diagram below can be Uised to make an optimum choice. Zone (B) represents a comfortable environment.

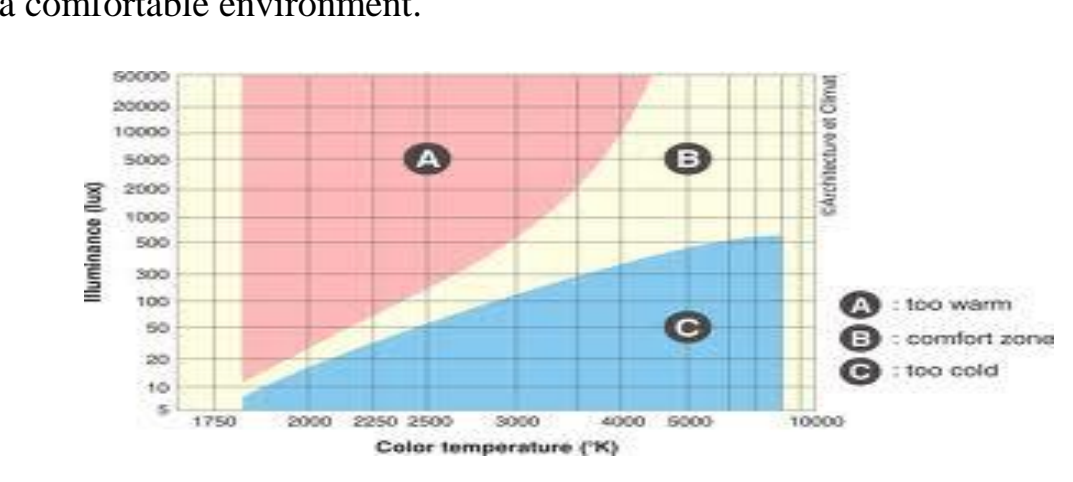

Figure 2. Kruithof Diagram

0.2. Unified Glare Rating (UGR): In recent years, the Unified Glare Rating (UGR) as recommended by the CIE (International Commission on Illumination) has become widely accepted as a general formula for assessing glare. The formula is given below:

$$
U G R=8 \log \frac{0,25}{L_{b}} \sum_{i=1}^{n} \frac{L_{i}^{2} \omega}{p^{2}}
$$

With: 
$L_{b}$ : background luminance (candela $/ \mathrm{m}^{2}$ ).

$p$ : Guth factor, given in specific tables, representing the position of a light with compared with the vertical axis.

$L_{i}$ : Luminance of the glare source (candela $\left./ \mathrm{m}^{2}\right)$.

$\omega$ : solid angle.

This formula is requires the prior knowledge of the position and brightness of each potential glare source. It is quite accurate but relatively difficult to work with. It is best used from within some computer software. For artificial light sources, such packages exist from most major producers of light fittings. They all require the modeling of the scene under investigation and produce a glare index for a defined position within the room.

\section{Table 1. Scale of Discomfort Associated with the UGR [14]}

\begin{tabular}{|c|c|}
\hline UGR & Sensation \\
\hline 10 & Perceptible \\
\hline 16 & Acceptable \\
\hline 22 & Uncomfortable \\
\hline 28 & Intolerable \\
\hline
\end{tabular}

c) Indoor air quality $(I A Q)$ : Indoor air quality can be indicated by the carbon dioxide $\left(\mathrm{CO}_{2}\right)$ concentration in a building [15]. The $\mathrm{CO}_{2}$ concentration comes from the presence of the inhabitants in the building and from various other sources of pollution. Ventilation is an important means for controlling indoor-air quality $(I A Q)$ in buildings. Supplying fresh outdoor-air and removing air pollutants and Codors from interior spaces is necessary for maintaining acceptable $I A Q$ levels. However, ventilation rates inside buildings must be seriously reduced in order focontrol the cooling or thermal load in an improved manner [16]. In many cases though, this contributes to a degradation of the indoor-air quality and to what is generally known as "sick building syndrome" $(S B S)$.

The association between carbon dioxide concentrations and occupant perceptions of the indoor environment in terms of comfort and irritation is complex because it mixes several different issues, including the comfort impacts of the carbon dioxide itself, associations between carbon dioxide levels and the concentrations of other occupant-generated contaminants, and the elationship between carbon dioxide and ventilation. Some indoor air quality investigators associate indoor carbon dioxide concentrations from $1100 \mathrm{mg} / \mathrm{m}^{3}(600$ ppm(v)) to $1800 \mathrm{mg} / \mathrm{m} 3(1000 \mathrm{ppm}(\mathrm{v}))$ or higher with perceptions of stuffiness and other indicators of discomfort. However, these associations are often based on anecdotal observations of the investigator or on informal occupant surveys [15].

Then, high rate of $\mathrm{CO}_{2}$ shows an important number of persons in space, probably reflecting a high concentration of pollutants in the air. Studies like [17] were then used to deternine a formula from the inside and outside $\mathrm{CO}_{2}$ concentration:

$$
P_{\text {ins }}=395 * e^{-15.15\left(\mathrm{CO}_{2}^{\text {int }}-\mathrm{CO}_{2}^{e x t}\right)^{-0.25}}
$$

With

$\mathrm{P}_{\text {ins: }}$ : Percentage of dissatisfied due to odors from the air inside. (\%)

$\mathrm{CO}_{2}{ }^{\text {int }}, \mathrm{CO}_{2}{ }^{\text {ext }}: \mathrm{CO}_{2}$ concentration in indoor, outside air. (ppm) 
d) Acoustic comfort: According Boulet [18], a suitable acoustic ambiance depends on three criteria, corresponding to the source of noise pollution (acoustic discomfort):

$>$ Acoustic discomfort from equipment, moving or activity.

$>$ Neighbor acoustic discomfort from adjoining dwellings.

$>$ The outside noise from transportation, neighboring buildings, nearby work, etc..

We characterize the noise by intensity criteria (noise level) and frequency. These two criteria are frequently united in the context of acoustic comfort, through $\mathrm{dB}$ (A) unit. For example, standard EN 15251 indicates a weighted acoustic pressure level between $25 \mathrm{~dB}$ (A) and $40 \mathrm{~dB}(\mathrm{~A})$ for residential rooms.

Unlike thermal comfort, acoustic comfort has also the disadvantage of not having a dynamic way to regulate the indoor environment. We can rarely control the noise, we can only limit or endure it [14].

2.4.2. Adaptive Comfort Model: To overcome the difficulties in measuring of different criteria sensory comfort in analytical methods, Humphreys has proposed an approach called adaptive approach [19], which states the following principle: If a change oceurs such as to produce discomfort, people react in ways which tend $O$ restore their comfort». He then sought to integrate physiological and behavioral adaptation in the measurements of thermal comfort.

In thermal comfort, the model can be set ap in a form that estimates the comfort temperatures $T c$ that is a complex adaptive function of the various circumstances $\mathrm{C}_{1}, \mathrm{C}_{2}, \mathrm{C}_{3},$. . etc., which operates on the indefinitely large set of conceivable adaptive actions that are potentially present within the adaptive model [19]. So we may write in functional notation:

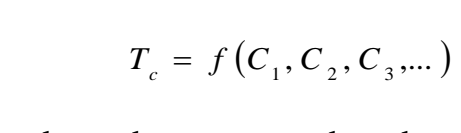

The adaptive model is based on the concept that there is a strong relationship between indoor comfort and outdor climate, taking into account that humans can adapt to, and tolerate different tempêfatures during different times of the year. The adaptive hypothesis predicts that contextual factors and pas thermal history modify building occupants' thermal expectations and preferences [20].

\section{Computational In elligence in Smart Home}

Application of intelligent methods to the control systems of buildings essentially started in the decade of the 1990s. Artificial Intelligence (AI) techniques were applied to the control of both conventional and bioclimatic buildings. Intelligent controllers, optimized by the use of evolutionary lgorithms were developed for the control of the subsystems of an intelligent building. The synergy of the neural networks technology, with fuzzy logic, and evolutionary algorithm resulted in the so-called Computational Intelligence (CI), which now has started to be applied in buildings.

The need to guarantee comfort conditions, taking into consideration the users' preferences, drove researchers to develop intelligent systems for energy and comfort management in buildings, mainly for large buildings like office buildings, hotels, public and commercial buildings, etc. A large number of publications regarding the application of fuzzy techniques found in the references. In [21], we presented the modeling and simulation of user preferences. We developed an original multi-sensory model able to ensure the satisfaction of occupants. Also, we combined the DEVS formalism and the theory of fuzzy logic to cope with the complexity of the system. 
Using Multi-agent systems, [22] proposed intelligent coordinator who receives as inputs PMV, IAQ, illumination level, energy consumption, occupants' preferences, and activation signals from the controllers-agents. It then performs two specific tasks using a master-slave coordination mechanism. Each task requires a separate intelligent agent. The dependency between the two tasks is that the lower level agent (slave) operates only when it receives an activation signal $r$ from the upper level agent (master).

\section{Proposed Adaptive System Overview}

The proposed adaptive system (See Figure 3) comprises several main components: Sensors, data preprocessing unit, actuators and adaptive controller that not only has the ability to assess a discomfort but also provides services to an inhabitant interacting on the actuators to restore a comfort. The adaptive controller is designed to work fully (multisensory comfort) in the background, and requires minimal effort of the occupants.

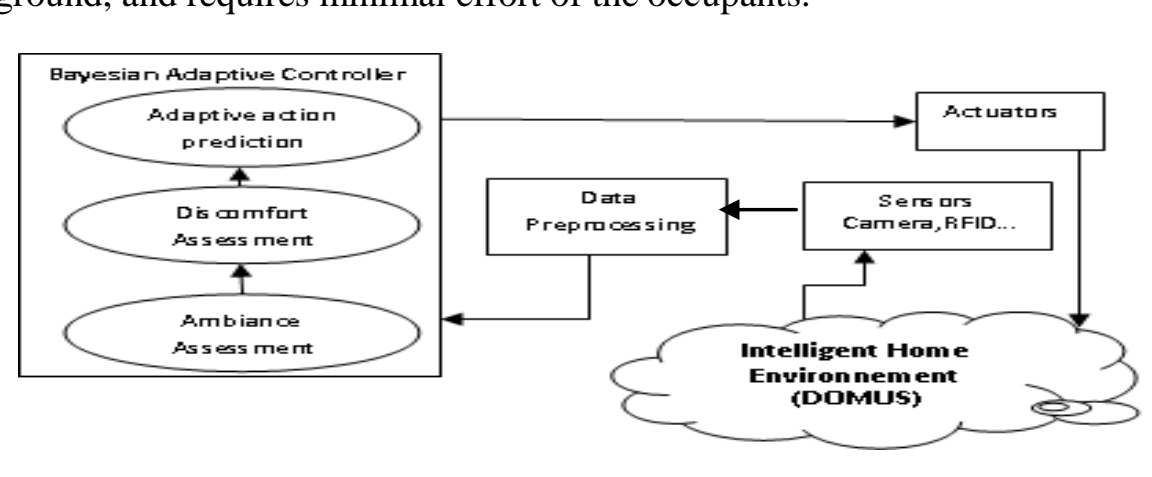

Figure 3. Adaptive System Overview

\subsection{Experimental Data Set}

Experimental data set is the most significant part of a research. The scenarios were played in the lab team Multicon which is the building CTL (center technology and software) at the University Joseph Fourier of Grenoble under the direction of Mr Jean Caelen. This lab contains an intelligent, building called DOMUS Figure 4, which is an apartment type F2 and fully equipped space, consisting of a kitchen, bedroom containing bed, TV and window shutters, shower, toilet, office that contains desk, computer and stereo, hallway, two fixed cameras in each room and two fixed cameras in the kitchen. The entire apartment is controlled by a home automation system that allows interaction with tangible objects and the collection of activity traces.

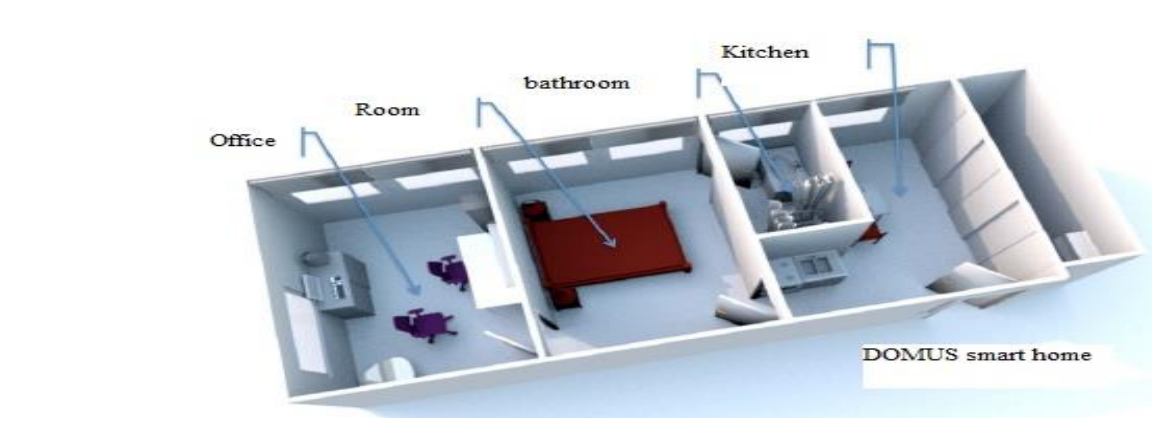

Figure 4. The DOMUS Smart Home 
A total of 20 people ( 8 males, 12 females) were asked to participate in the research work. They were asked to spend about 1 hour and a half in the intelligent flat. The experiment was divided in 3 slots of 20 to 30 minutes, each one of them in a specific room with a specific activity. Also, inhabitants were asked to fill a form every five minutes in order to understand their perception of comfort with a sensorial semantic (see Table 2). Each of these variables was presented in the form of a Likert scale to the inhabitant. Answers were transposed into quantitative data for analysis, ranging from 0 for « very unpleasant » to 10 for « very pleasant », after receiving the sensory data we define the change from a state of an object to another as an "interaction".

The questionnaire was implemented in an electronic and mobile way in order to facilitate the user's annotations.

Table 2. User's Perceptions Questionnaire

\begin{tabular}{ll}
\hline \hline Name & (Likert) Scale legend \\
\hline Global comfort & Very unpleasant to very pleasant \\
Thermal comfort & Very unpleasant to very pleasant \\
Lighting comfort & Very unpleasant to very pleasant \\
Air quality & Very unpleasant to very pleasant \\
Acoustic comfort & Very unpleasant to very pleasant \\
\hline \hline
\end{tabular}

\subsection{Proposed Bayesian Model Construction}

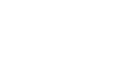

For design our controller model, several issues need to be addressed. The first issue is how to preprocess sensor data such that the oreprocessed sensory data can be utilized to extract informative features. The second issue is how to choose among these informative features to represent a controller model effectively. The last issue is how to train the parameters of controller model from the selected informative features so that interactions with actuators can be successfully inferred.

To take into account comfort information and relationship between an interaction and its corresponding informative features, we use Bayesian Network (DBN), which models ambiance information and predictsprobability of an interaction. Figure 5 shows the graphical structure of our proposed Bayesian model.

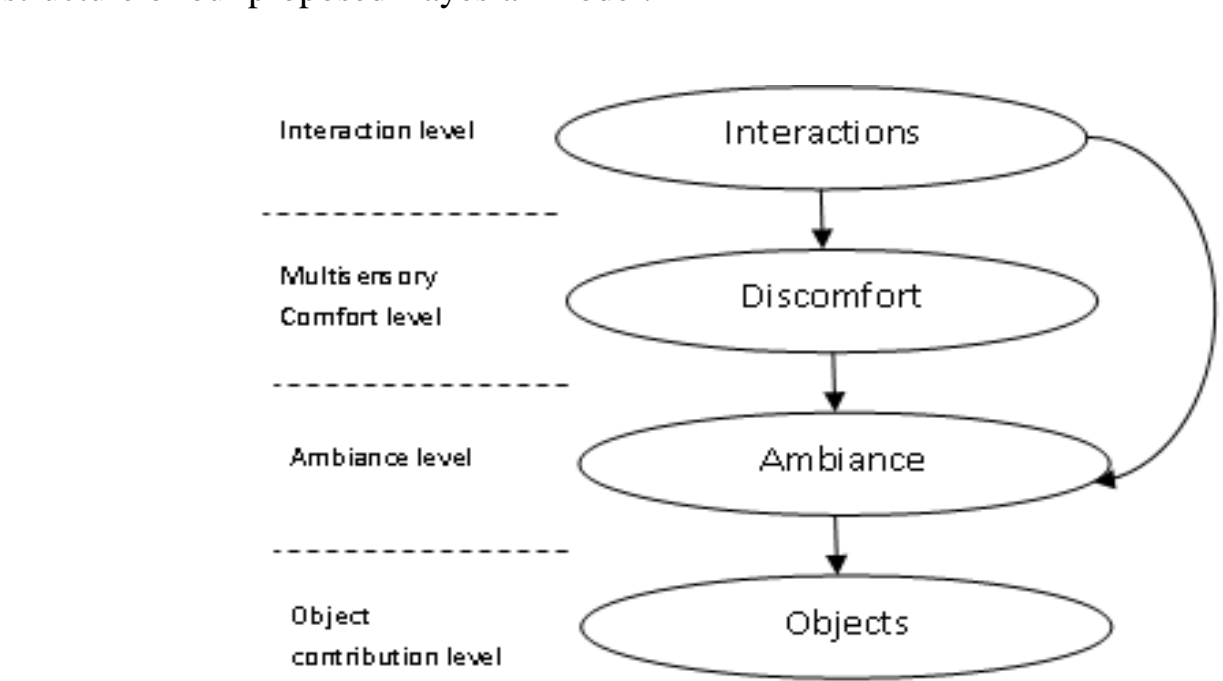

Figure 5. Proposed Network Byesian Model 
This proposed Bayesian network models the temporal information for objects (sensors), ambiance and multisensory discomfort, and then we use this probabilistic network to predict appropriate action which restores a comfort. Each level is formally represented by a vector, the ambiance vector is expressed by $A=\left(A_{T}, A_{V}, A_{I}, A_{A}\right)$, (thermal, visual, indoor air quality and acoustic ambiance), which are measured in the Likert scale (Very unpleasant to very pleasant). The interaction vector is denoted by $I=\left(I_{1}, I_{2}, I_{3}, \ldots, I_{N}\right)$ which represents all the interactions on actuators, for example I1 is the interaction with lamp and its values are: turn on, turn off or don't change. The object vector is denoted by $O=\left(O_{1}, O_{2}, O_{3}, \ldots, O_{K}\right)$ when $O_{n}=o_{i}$ represents state $o_{i}$ of an object $O_{n}$.

The corpus data (observations) allow us to estimate the conditional probability distributions that can be made by a simple calculation of frequencies (Maximum Likelihood). However, when a value of an attribute A does not occur with a given value of its parent node $B$, the estimate of $P(A \mid B)$ produces a null value, and makes the prediction step difficult. To overcome this problem, we use the Laplace estimator.

\subsection{Interactions Prediction}

Our goal is to show how infer (predict) interactions with the actuators of the building given the current context (ambiance and discomfort) recently observed. This prediction of interactions can be expressed by the probability $P$ (Interaction DAmbiance, Discomfort) such as:

$P(I=j \mid A, D)>P(I=k \mid A, D) \forall k \neq$. which $1=j$ is the selected (inferred) interaction, $D$ is the discomfort and $\mathrm{A}$ is the multisensory ambiance

To calculate the probability $P(N \mid A, D)$, the local joint probability is used, we have: so
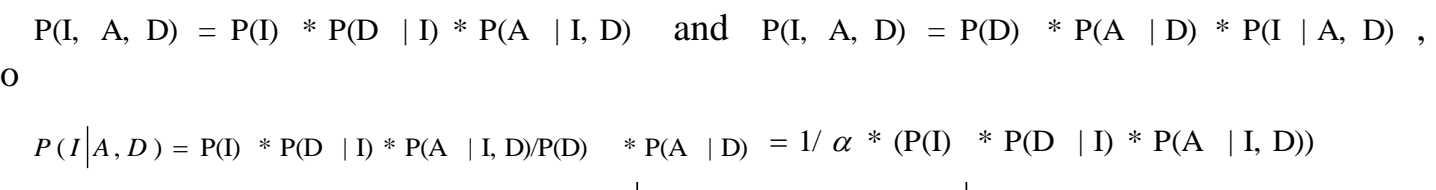

Note that for the probability $P(I=i \mid A, D)$ and $P(I=i \mid A, D), \alpha$ is constant, so to compare these two pobabilities it is done by calculating the $\mathrm{P}(\mathrm{I}) * \mathrm{P}(\mathrm{D} \mid \mathrm{I}) * \mathrm{P}(\mathrm{A} \mid \mathrm{I}, \mathrm{D} \bigcirc$ numerator for $\mathrm{I}=\mathrm{j}$, and $\mathrm{I}=\mathrm{k}$, with $\mathrm{P}(\mathrm{I}), \mathrm{P}(\mathrm{D} \mid \mathrm{I})$ and $\mathrm{P}(\mathrm{A} / \mathrm{L}, \mathrm{D})$ are parameters of our Bayesian network.

\subsection{The Correlation between the Multi-Sensorial Comfort and Specific Ambiances}

The goal now is to predict the discomfort knowing the current specific ambiances. For this, we focused on a Bayesian approach (Figure 6), which is inspired from the work of Rohles [23], where the multisensory comfort is provided by a linear weighting according to the following formulation:

Confort Global $=\mathrm{a} *$ Confort ${ }_{\text {Thermal }}+\mathrm{b} *$ Confort $\quad$ Visual $+\mathrm{c} *$ Confort $\quad$ olfactory $+\mathrm{d} *$ Confort Acoustic 


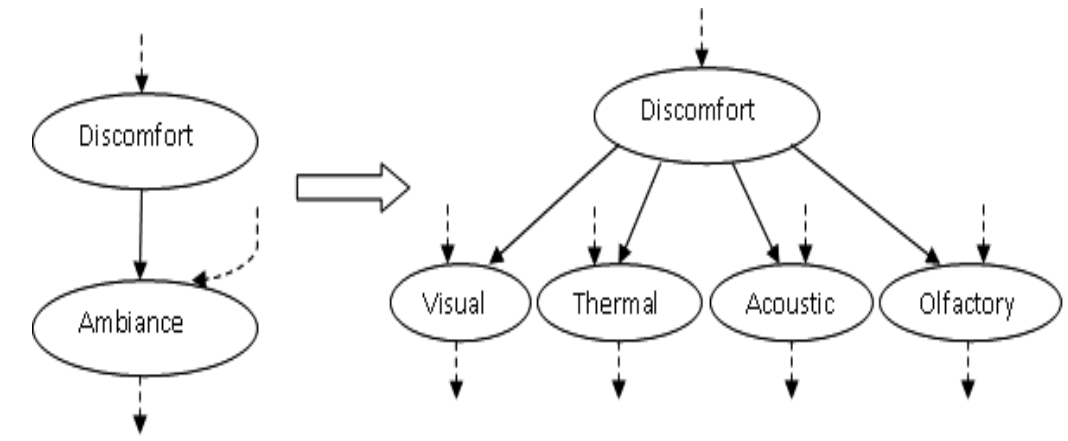

Figure 6. The Bayesian Network used for the Analysis of Multisensory Comfort

Formally, the objective is to estimate the probability $P(D \mid A)$, for this we will use Bayes' rule and the local joint probability $P(D, A, I)$.

$$
P(D \mid A)=\frac{P(D, A)}{P(A)}=\frac{\sum_{I} P(D, A, I)}{P(A)}=\frac{\sum P(I) P(D \mid I) P(A \mid D, I)}{P(A)}
$$

Note that for all values di of $\mathrm{D}, 1 / P$ ( $)$ is constant, so to compare the probabilities $P\left(D=d_{i} \mid A\right)$ and $P\left(D=d_{k} \mid A\right)$ it suffices to calculate:

$$
\Sigma_{i}(P(I=i) * P(D-1=i) * P(A \mid,=i, D)) \text { for } \mathrm{D}=\mathrm{di} \text { and } \mathrm{D}=\mathrm{dk} \text {. }
$$

Where $P(I), P(D \mid I)$ and $P(A \mid I, D)$ are parameters (already calculated) of our Bayesian network.

\subsection{The Correlation between Specific Ambiances and Objects}

To characterize the ambiance to be confronted with the judgment of the occupants, we propose a Bayesian model that presents different contributions of smart objects in each sensory domain. At this lever the goal is to predict the values of the specific ambiance (elementary) vis-a-vis the sfate of all objects (sensors) of our environment. Formally we calculate the probability (Ambiance | Objects).

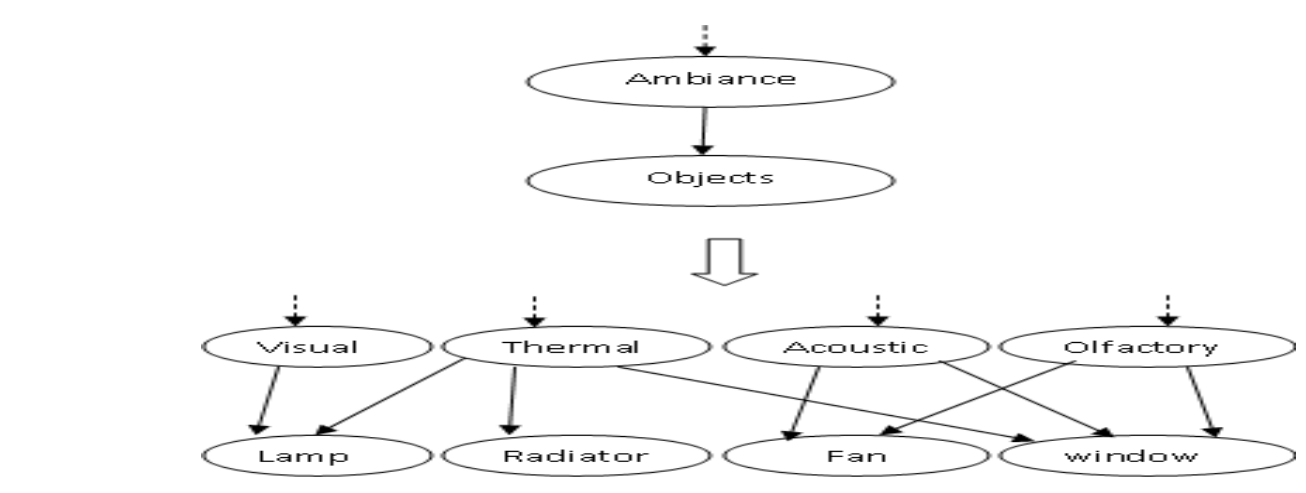

Figure 7. The Bayesian Structure Modeling Domain of Object Contribution in Comfort 
Using Bayes' rule, we have:

$$
P(A \mid O)=\frac{P(A) * P(O \mid A)}{P(O)}
$$

Note that for different values $a_{i}$ in $P\left(A_{s}=a_{i} \mid O\right), 1 / \mathrm{P}(\mathrm{O})$ is constant, so to compare the probabilities of the different values $a_{i}$ of a specific ambiance $A_{s}$, where s designates type of specific ambience(thermal, visual, i-A-Q or acoustic ambiance), knowing the same state of objects (sensors), it suffices to compare the numerators of this probabilities :

$P\left(A_{S}=a_{i}\right) * P\left(O \mid A_{S}=a_{i}\right)$ which $P\left(O \mid A_{S}=a_{i}\right)$ is a parameter of our Bayesian network. So to calculate $P\left(A_{S}=a_{i}\right)$ we will use the marginalization of local joint probability $P(A, I, D)$, so we have :

$$
P\left(A_{S}=a_{i}\right)=\sum_{I} \sum_{D} P\left(A_{S}=a_{i}, I, D\right)=\sum_{I} \sum_{D} P(I) * P(D \mid I) * P\left(A_{S}=a_{i} I, D\right)
$$

Which $P(I), P(D \mid I)$ and $P(A \mid I, D)$ are parameters (already calculated) of our Bayesian network.

\subsection{Results and Validation}

At this stage, we want to know the validity and performance of the model. The goal is to show that the result of the inference on the proposed model is closer to reality. For this, we used the method of cross-validation "N-fôld cross-validation", that is a statistical method of evaluating and comparing learning algonthms by dividing data into two segments: one used to learn or train a model and the other used to validate the model. Therefore, learning from the corpus, excluding annotations of $\delta_{i}$ for testing, and start learning $n$ times by changing the subject $\mathrm{Si}$, The empirical error rate $R_{\text {real }}{ }^{2}$ on the sample $i$ (annotations of $S_{i}$ ) becomes the number (percentage) of pooly inferred interactions compared to those annotated by the subject $S_{i}$, and the final estimated error $R_{\text {real }}$ is given by the average of the measured errors $\hat{R}_{\text {real }}^{i}$. The result of this performance analysis is illustrated in Figure 8.

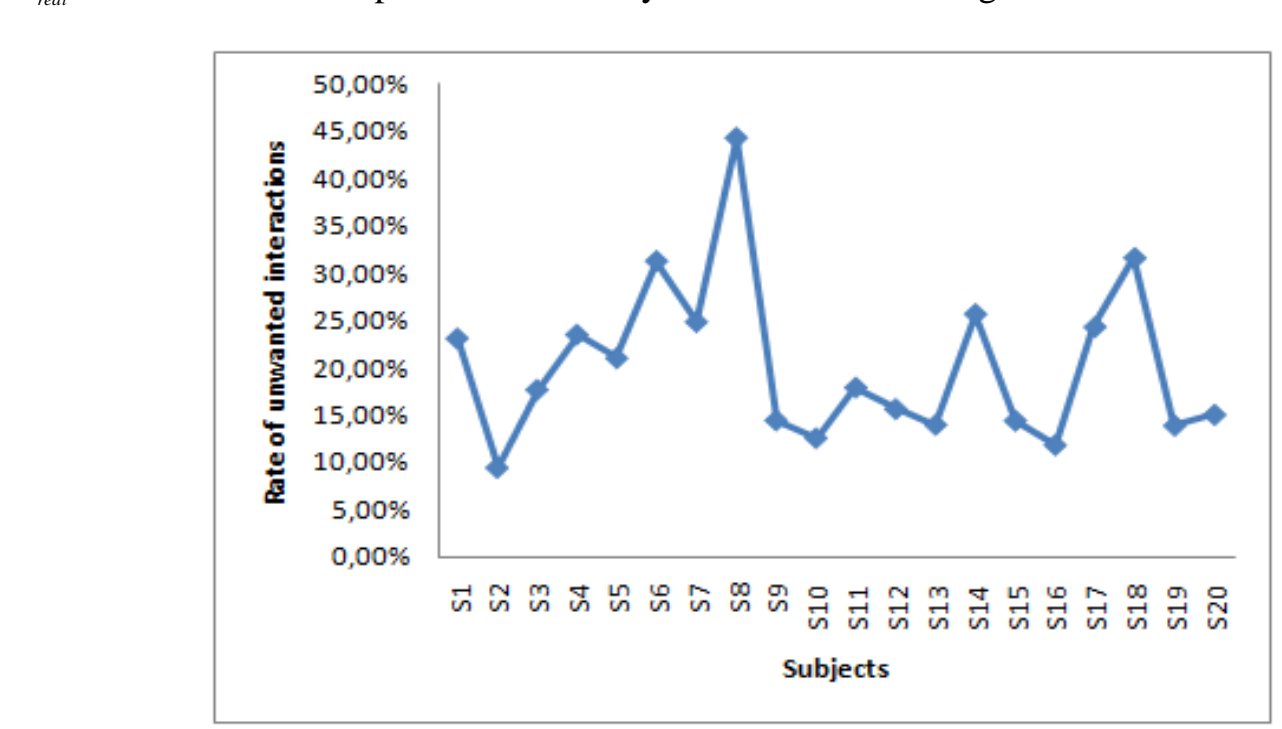

Figure 8. Rate of Inferred Undesirable Interactions per Subject 
The results of this analysis indicate that $80 \%$ of inferred interactions (predicted) on the model satisfy all subjects, while $20 \%$ of inferred interactions are undesirable, which indicates the subjectivity of comfort.

\section{Conclusion}

In this work, we are interested to the concept of multisensory comfort in intelligent building. For this, we had to define the concept of this intelligent building. Then, we are interested, in particular, to the ambiance comfort, considering four areas: thermal comfort, visual comfort, olfactory comfort and acoustic comfort. Modeling the ambiance comfort can be done independently of each of these areas, or globally, multi-sensory, as we propose.

We proposed, in line with the possibilities offered by the smart home, a layered Bayesian model: first layer to characterize the contribution of objects in each specific ambiance, the other modeling multi-sensory comfort, the last allowing, after evaluating discomfort, a prediction of interactions to restore the comfort. All of this work was based on the intelligent Domus apartment, which served as a place of integration for the first part, and place of experimentation for the second.

\section{Acknowledgements}

I thank all Multicom team, including Professor Jean Caelen who welcomed us into his laboratory, and has consecrated for us the platform DOMUS for the realization of our experiences.

\section{References}

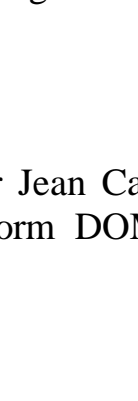

[1] C. Sèze, "Confort moderne: unế nouvêlle culture du bien-être ", Éditions Autrement,Paris (1994).

[2] P.O.Fanger, "Assessment of man's thermâl comport in practice", British Journal of Industrial Medicine, vol. 30, n. 4, (1973), pp. 313-324.

[3] B. Givoni and J.L.Izard, Dhomme l'architecture et le climat", Éditions du Moniteur,Paris (1978).

[4] P. Rashidi and D.J. Crok Adapting to Resident Preferences in Smart Environments", in National Conference on Artificial Intelligence (AAAI) (2008).

[5] Y. H. Chen, C. H Lu, K.C. Hsu, D.C.Fu, Y.J. Yeh and L.C. Kuo, "Preference Model Assisted Activity Recognition Learning in a Smart Home Environment", in IEEE/RSJ International Conference on Intelligent Robôts and Systems, (2009), pp 4657 - 4662.

[6] M. Barry, "Intelligent buildings", IEEE Communications Magazine, Vol. 29,(1991), pp.24-27.

[7] American Society of Heating, Refrigerating and Air-conditioning Engineers handbook 2005, fundamentals, ASHR AE (2005).

[8] V. Candas and A.Dufour, "Thermal Comfort: Multisensory Interactions?" , Journal of Physiological Anthropology and Applied Human Science, vol. 24, n. 1, pp. 33-36. (2005).

[9] L. Fang, C.Clausen, and P.O.Fanger, "Impact of Temperature and Humidity on the Perception of Indoor Ayr Quality". International Journal of Indoor Environment and Health, vol. 8, n.2, pp. 8090,(1998).

[10] M. O.Ernst, and M. S.Banks, "Humans integrate visual and haptic information in a statistically optimal fashion", Nature, vol. 415, n. 6870, pp. 429-433. (2002).

[11] T.Hospedales and S.Vijayakumar, "Multisensory oddity detection as bayesian inference", PLOS ONE journal, vol. 4, n. 1, (2009).

[12] PO.Fanger, "Thermal comfort: analysis and applications in environmental engineering", Danish Technical Press, New York: McGraw-Hill; (1972).

[13] M.Bodart, "Création d'un outil d'aide au choix optimisé du vitrage du bâtiment, selon des critères physiques, économiques et écologiques, pour un meilleur confort visuel et thermique", Thesis, Catholic University of Louvain. (2002). 
[14] M. Gallissot, “ Modéliser le concept de confort dans l'habitat intelligent : du multisensoriel au comportement", Thesis, University Joseph Fourier, Grenoble, (2012).

[15] S. J. Emmerich and AK.Persily, "State-of-the-art review of CO2 demand controlled ventilation technology and application". NISTIR 6729, National Institute of Standards and Technology, Technical report, (2001).

[16] A.I. Dounis , C. Caraiscos, "Advanced control systems engineering for energy and comfort management in a building environment-A review", Renewable and Sustainable Energy Reviews, vol. 13, n. 6-7, (2009), pp. 1247.

[17] European Collaborative Action, "Guidelines for Ventilation Requirements in Buildings", Environement and Quality of Life, Report $n^{\circ} .11,(\mathbf{1 9 9 2})$.

[18] S.Boulet, "Caractérisation du confort hygrothermique et acoustique dans les constructions à base de bois". Thesis, University of Savoie, (2009).

[19] J.F.Nicol, " Understanding the adaptive approach to thermal comfort", ASHRAE transactions Symposia, vol. 104, n. 1b, pp. 991-1004, (1998).

[20] R.de Dear and G. S.Brager, "Developing an adaptive model of thermal comfort and preference", ASHRAE Transaction, vol. 104, n. 1a, pp. 145-167, (1998).

[21] L. Aid, L. Zaoui and S.A. Mostefaoui, “A Multi-Sensory Approach Integrating UserPreferences”, IACSIT Int. J. Eng. Tech., vol. 5, n. 1, (2013), pp. 68-72.

[22] A.I. Dounis and C. Caraiscos, "Advanced control systenis engineering for energy and comfort management in a building environment-A review", Renewable and Sustainable Energy Reviews, vol. 13, n. 6, pp. 1246-1261, (2009).

[23] F. H. J.Rohles, J. E. J.Woods and P. R.Morey, Indoor enviconment acceptability: the development of a rating scale”. ASHRAE transactions, vol. 95, pp. 23-27, (1989).
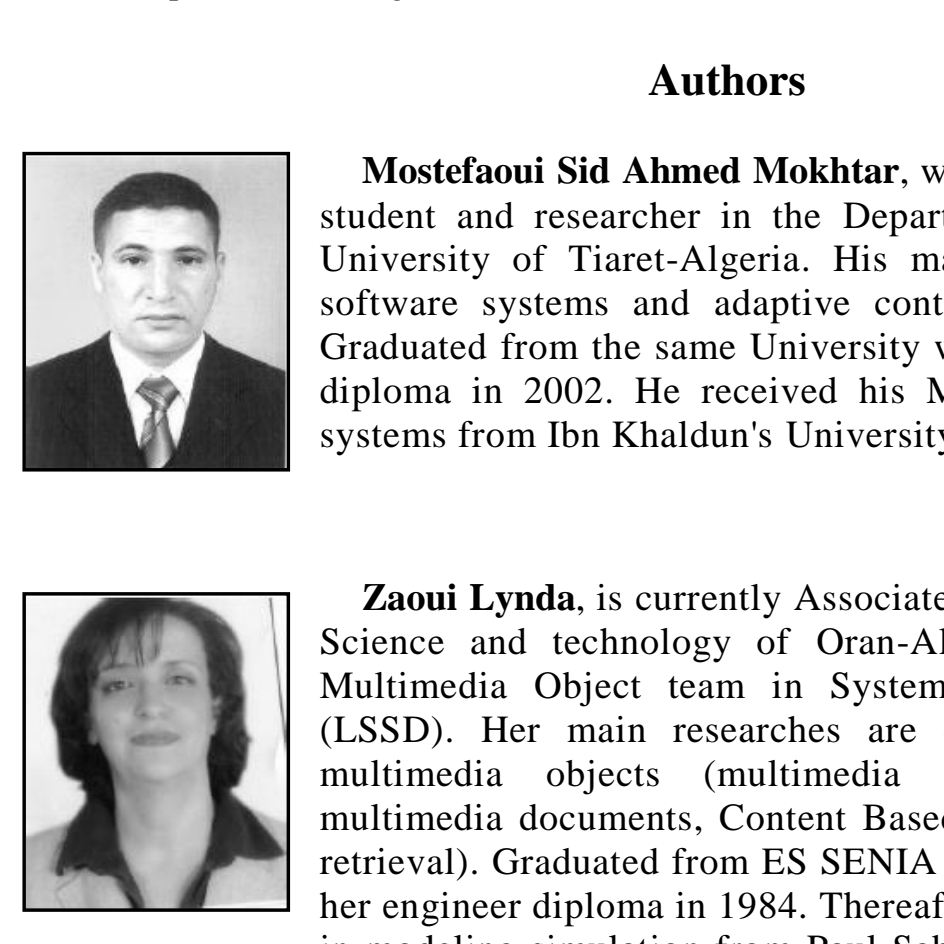

Mostefaoui Sid Ahmed Mokhtar, was born in Algeria, he is a Phd student and esearchet if the Department of computer science at University of Tiaret Algeria. His main research interests include software systems and adaptive control systems in smart spaces. Graduated from the same University where he received his engineer diploma in 2002. He received his MSC in computer information systems from Ibn Khaldun's University of Tiaret in 2010.

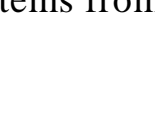

Zaoui Lynda, is currently Associate Professor at the University of Science and technology of Oran-Algeria. She is responsible of Multimedia Object team in System-Signal and Data laboratory (LSSD). Her main researches are centered on manipulation of multimedia objects (multimedia mining, synchronization of multimedia documents, Content Based Image retrieval, information retrieval). Graduated from ES SENIA University where she received her engineer diploma in 1984. Thereafter, she gained an MSC (DEA) in modeling simulation from Paul Sabatier University (Toulouse) in 1985 and received Phd degree in computer Sciences in 1987 from the same University. She received a Doctorat degree in 2006 from the university of Science and Tchnology of Oran. 


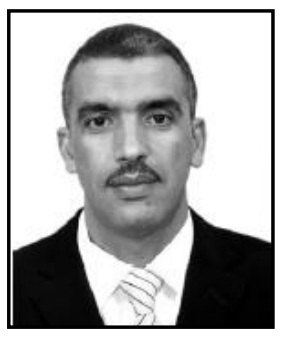

AID Lahcene, is a postgraduate student and researcher in the Department of computer science at University of science and technology of Oran-Algeria. His research interests include pervasive measurement systems for intelligent environments and adaptive, Intelligent Systems Modelling and Simulation. Graduated from the same University where he received his engineer diploma in $1999 . \mathrm{He}$ received his MSC (Magister) in computer information systems from Ibn Khaldun's University of Tiaret in 2011.

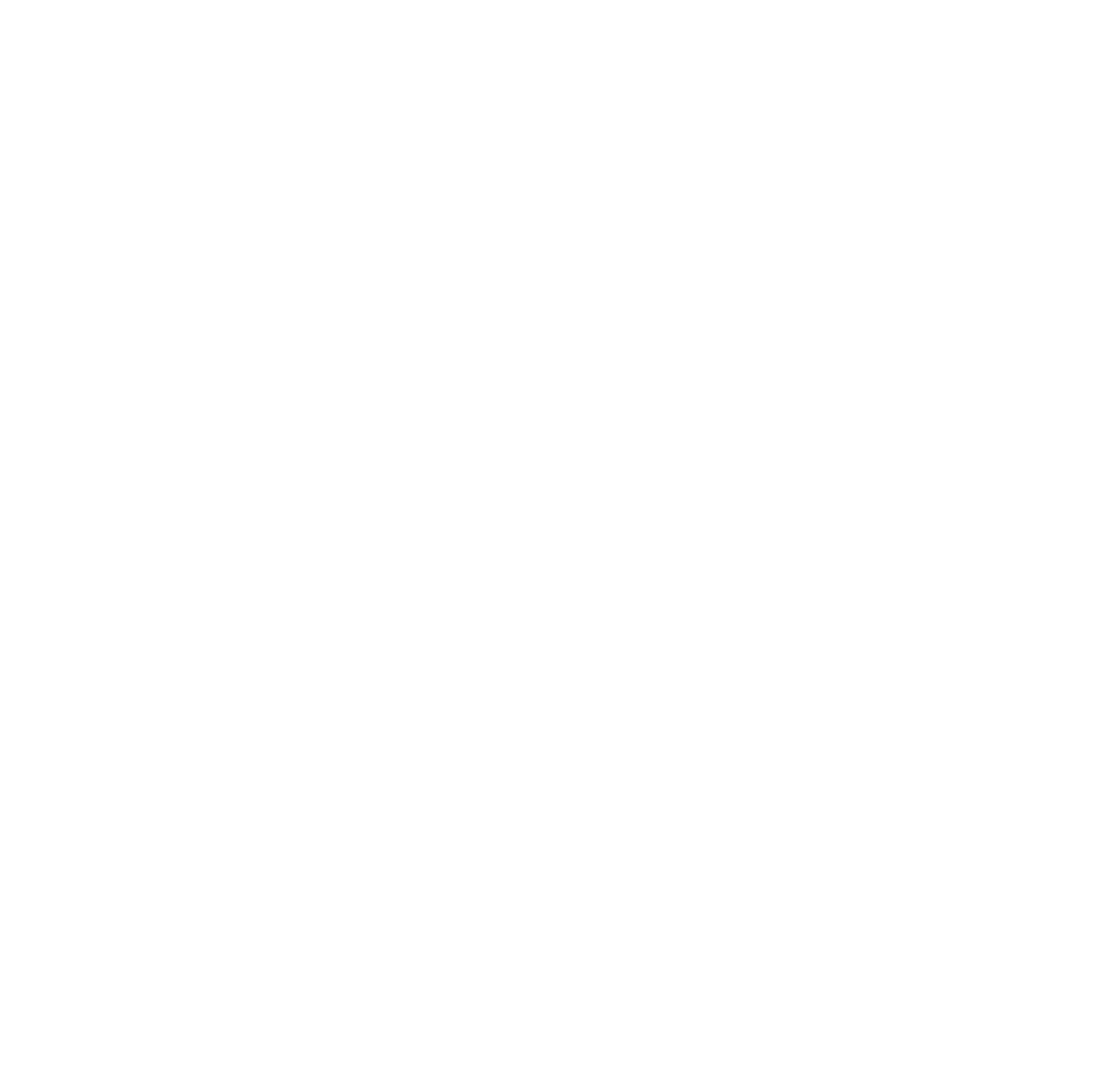


International Journal of Smart Home

Vol.8, No.5 (2014)

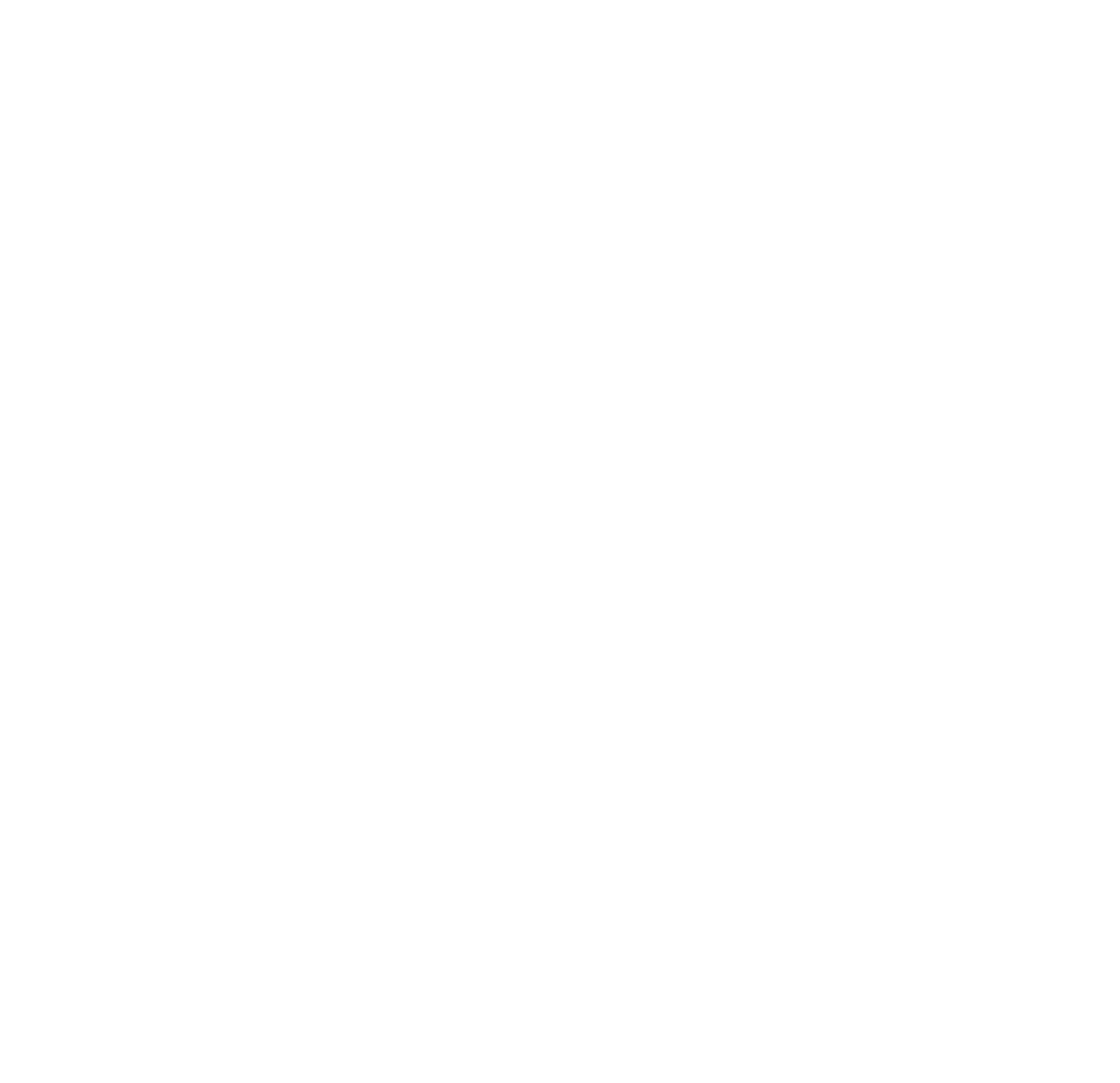

